OPEN ACCESS

Edited by:

Edvaldo Antonio Ribeiro Rosa, Pontifícia Universidade Católica do

Paraná, Brazil

Reviewed by:

Luis Antonio Pérez-García, Universidad Autónoma de San Luis Potosí, Mexico Osmar Nascimento Silva, Universidade Católica Dom Bosco,

Brazi

${ }^{*}$ Correspondence: Ana M. Fusco-Almeida ana.marisa@uol.com.br Kaila P. Medina-Alarcón kaylabiotech@gmail.com

Specialty section:

This article was submitted to Antimicrobials, Resistance and Chemotherapy,

a section of the journal

Frontiers in Microbiology

Received: 15 March 2017 Accepted: 26 May 2017

Published: 12 June 2017

Citation:

Medina-Alarcón KP, Singulani JL, Voltan AR, Sardi JCO, Petrônio MS,

Santos MB, Polaquini $C R$,

Regasini LO, Bolzani VS, da Silva DHS, Chorilli $M$,

Mendes-Giannini MJS and

Fusco-Almeida AM (2017) Alkyl

Protocatechuate-Loaded

Nanostructured Lipid Systems as

a Treatment Strategy

for Paracoccidioides brasiliensis and Paracoccidioides lutzii In Vitro.

Front. Microbiol. 8:1048.

doi: 10.3389/fmicb.2017.01048

\section{Alkyl Protocatechuate-Loaded Nanostructured Lipid Systems as a Treatment Strategy for Paracoccidioides brasiliensis and Paracoccidioides lutzii In Vitro}

Kaila P. Medina-Alarcón ${ }^{*}$, Junya L. Singulani ${ }^{1}$, Aline R. Voltan ${ }^{1}$, Janaina C. O. Sardi ${ }^{1}$, Maicon S. Petrônio ${ }^{2}$, Mariana B. Santos², Carlos R. Polaquini², Luis O. Regasini², Vanderlan S. Bolzani ${ }^{3}$, Dulce H. S. da Silva ${ }^{3}$, Marlus Chorilli4, Maria J. S. Mendes-Giannini ${ }^{1}$ and Ana M. Fusco-Almeida ${ }^{1 *}$

${ }^{1}$ Mycology Laboratory and Nucleus of Proteomics, Department of Clinical Analysis, School of Pharmaceutical Sciences, São Paulo State University, Araraquara, Brazil, ${ }^{2}$ Department of Chemistry and Environmental Sciences, Institute of Biosciences, Humanities and Exact Sciences, São Paulo State University, São José do Rio Preto, Araraquara, Brazil, ${ }^{3}$ Department of Chemistry, Institute of Chemistry, São Paulo State University, Araraquara, Brazil, ${ }^{4}$ School of Pharmaceutical Sciences, Department of Drugs and Medicines, São Paulo State University, Araraquara, Brazil

Dodecyl protocatechuate (dodecyl) is a derivative of protocatechuic acid (3,4dihydroxybenzoic acid) that possesses anti-oxidant and antifungal properties. Nanostructured lipid systems (NLS) can potentiate the action of many antifungal agents, reducing the required dose and side effects by improving their activity. This work aimed to evaluate dodecyl protocatechuate loaded into a NLS (NLS+dodecyl) as a strategy for the treatment of Paracoccidioides brasiliensis and $P$. lutzii in vitro. Antifungal activity against $P$. brasiliensis and $P$. lutzii was evaluated using the microdilution technique. $\mathrm{NLS}+$ dodecyl showed high antifungal activity with a minimum inhibitory concentration ranging from 0.06 to $0.03 \mu \mathrm{g} / \mathrm{mL}$; 4- to 16 -fold higher than that of free dodecyl. NLS+dodecyl was able to inhibit fungal adhesion of the extracellular artificial matrix proteins (laminin and fibronectin), resulting in 82.4 and $81 \%$ inhibition, respectively, an increase of $8-17 \%$ compared with free dodecyl. These findings corroborate previous results demonstrating 65 and $74 \%$ inhibition of fungal adhesion in pulmonary fibroblast cells by dodecyl and NLS+dodecyl, respectively, representing a 9\% increase in inhibition for NLS+dodecyl. Subsequently, cytotoxicity was evaluated using the $0.4 \%$ sulforhodamine B assay. NLS+dodecyl did not exhibit cytotoxicity in MRC5 (human pneumocyte) and HepG2 (human hepatic carcinoma) cells, thus increasing the selectivity index for NLS+dodecyl. In addition, cytotoxicity was evaluated in vivo using the Caenorhabditis elegans model; neither dodecyl nor NLS+dodecyl exhibited any toxic effects. Taken together, these results suggest that NLS can be used as a strategy to improve the activity of dodecyl against $P$. brasiliensis and $P$. lutzii because it improves antifungal activity, increases the inhibition of fungal adhesion in lung cells and the extracellular matrix in vitro, and does not exhibit any toxicity both in vitro and in vivo.

Keywords: dodecyl, nanostructured lipid system, Paracoccidioides brasiliensis, Paracoccidioides lutzii, antifungal 


\section{INTRODUCTION}

Paracoccidioidomycosis, which is one of the most important systemic mycoses in Latin America, is a disease caused by the dimorphic fungi Paracoccidioides brasiliensis and P. lutzii. PCM is found from southern Mexico to northern Argentina and especially in Brazil, where the greatest number of cases have been reported (San-Blas et al., 2002; Colombo et al., 2011; Hernández et al., 2011; Alvarenga et al., 2016). Human infection by Paracoccidioides spp. occurs primarily through the respiratory system via inhalation of spores in the mycelial form, which transform into yeast following an increase in temperature. The disease can develop immediately following infection or even years later, depending on fungal virulence, its ability to interact and invade the surface of the cell, and the host immune response (Mendes-Giannini et al., 2000; Marcos et al., 2012; de Souza et al., 2014; de Oliveira et al., 2015). Virulence factors can be divided into two categories: those that promote colonization and invasion and those that harm the host such as toxins and proteinases. Adherence refers to pathogen recognition of ligands on the surface of the host cell or constituents of the basement membrane such as fibrinogen, laminin, collagen, and fibronectin. Several types of collagen are present in the interstitium, particularly as part of fiber lattices, which constitute target molecules for fungal, parasite, and bacterial infection (González et al., 2005; Marcos et al., 2012; de Oliveira et al., 2015) .

Abbreviations: AMB, amphotericin; ATCC, American type culture collection; CFU, Colony forming unit; CLSI M27-A3, clinical and laboratory standards institute M27-A3 Reference Method for Broth Dilution Antifungal Susceptibility Testing of Yeasts; DMSO, Dimethyl sulfoxide; ECM, extracellular matrix; EG/SEM, high resolution scanning microscopy; EtOAc, ethyl acetate; HepG2, human liver carcinoma cells; ITC, itraconazole; MIC, minimum inhibitory concentration; MRC5, human normal pneumocyte cells; NLS+dodecyl, dodecyl protocatechuate loaded-nanostructured lipid system; NLS, nanostructured lipid system; OS, sodium oleate; PBS, phosphate-buffered saline; PC, phosphatidylcholine; PCM, paracoccidioidomycosis; PDI, polydispersity index; SI, selectivity index.
Amphotericin B (AMB) is a drug of first choice for severe PCM, regardless of the immune status of the patient. AMB causes many side effects, such as nephrotoxicity, in patients, thus making conventional therapy difficult (Shikanai-Yasuda et al., 2006; Bocca et al., 2013). Other treatments, such as the use of corticosteroids, have been reported as adjuvant therapies in the treatment of infectious diseases, including PCM; these aim to reduce the inflammatory response of the host, which can result in tissue damage and organic dysfunction (Benard et al., 2012). Ketoconazole is classified as moderately effective for mycosis treatment; it was replaced by ITC because of its low absorption and adverse effects. Although ITC is more active, it produces many drug interactions and consequently causes several side effects (Naranjo et al., 2010; Shikanai-Yasuda, 2015). Antifungal resistance and at-risk patient populations are increasing. Furthermore, the number of commercially available antifungal drugs, many of which still present numerous side effects, is restricted. Together, these issues emphasize the need to develop new antifungal substances from natural sources (Nishioka, 1996; Lortholary et al., 1999; Shikanai-Yasuda, 2015).

Protocatechuic acid, also known as 3,4-dihydroxybenzoic acid, is found in fruits, nuts, and vegetables including olives, rice, tea, white wine, and herbal medicines. Their alkyl derivatives are shown in Figure 1. Phenolic compounds have been widely studied for their pharmacological activities and for their ability to inhibit lipid oxidation and the proliferation of fungi (Lin et al., 2009; Soares et al., 2014; Khan et al., 2015). The chemical complexity of compounds is important for their incorporation into a vehicle that will enable release of the active ingredient and the biological response (Bonifácio et al., 2015).

Technological strategies, including NLSs, such as microemulsion, offer efficient compartmentalization and oral
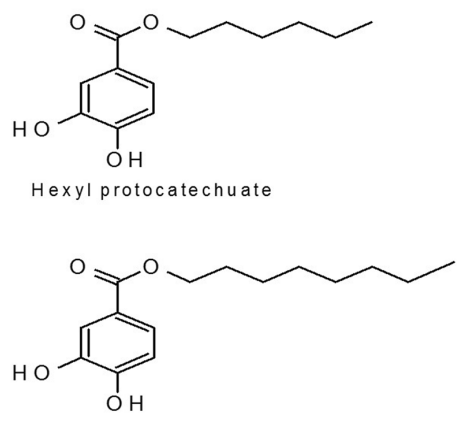

Octyl protocatechuate

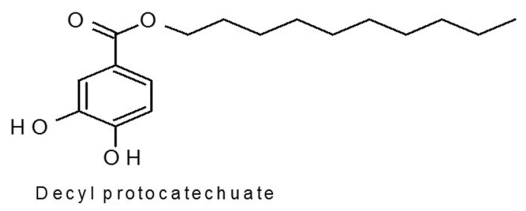

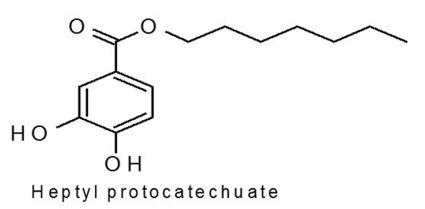
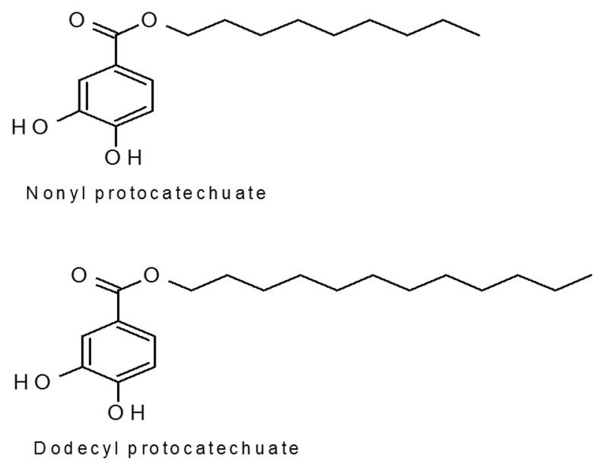

FIGURE 1 | Protocatechuate structures. 
bioavailability and improve the solubility of several active groups. Lipid-based drug delivery systems are used in the development of products because of their versatility with pharmaceutical excipients and their compatibility with liquid, semi-solid, and solid pharmaceutical forms (Cerpnjak et al., 2013).

Previous studies using AMB have shown that the presence of lipids in nanoemulsions and microemulsions enabled their successful delivery in respiratory therapy (Nasr et al., 2012; Hussain et al., 2014). Other lipid formulations of AMB are used to treat severely disseminated infections such as PCM, histoplasmosis, mucormycosis, and cryptococcosis (Roberts et al., 2015).

In addition, a recent study of compound and nanoparticle toxicity was performed in the in vivo model Caenorhabditis elegans (Okoli et al., 2009; Contreras et al., 2014; Rogers et al., 2015; Muhammed et al., 2016). This free-living nematode presents various advantages such as a short life cycle (3-4 days at $\left.20^{\circ} \mathrm{C}\right)$, small size $(1 \mathrm{~mm})$, transparency, easy cultivation, and a well-characterized genome (Kaletta and Hengartner, 2006; Peterson et al., 2008).

The aim of this study was to investigate the effects of dodecyl protocatechuate-loaded in NLS (NLS+dodecyl) as a strategy for improving the antifungal activity of free dodecyl protocatechuate against Paracoccidioides spp. in vitro. Moreover, we evaluated the toxicity of free and NLS-incorporated dodecyl protocatechuate in MRC5 and HepG2 cells and in the C. elegans model.

\section{MATERIALS AND METHODS}

\section{Compounds}

Alkyl derivatives of protocatechuic acid were prepared using esterification reactions as described by de Faria et al. (2012) with minor modifications. Three milliliters of $\mathrm{N}, \mathrm{N}^{\prime}$ dicyclohexylcarbodiimide (DCC, $1.0 \mathrm{mmol}$ ) in dry p-dioxane was added to $0.2 \mathrm{mmol}$ of cooled $\left(5^{\circ} \mathrm{C}\right)$ protocatechuic acid and $20 \mathrm{mmol}$ of n-alkyl in $6.0 \mathrm{~mL}$ of dry p-dioxane. After $48 \mathrm{~h}$, the solvent was removed under reduced pressure. The residue was partitioned with EtOAc $(3 \times$ EtOAc $)$ and filtered. The filtrate was washed successively with a saturated aqueous citric acid solution $(3 \times)$ and with saturated aqueous $\mathrm{NaHCO}_{3}(3 \times)$. The organic phase was dried over anhydrous $\mathrm{MgSO}_{4}$ and evaporated under reduced pressure. The crude products were purified over a silica gel column and eluted isocratically with $\mathrm{CHCl}_{3} / \mathrm{MeOH}(98: 2)$ to yield esters. Their structures were confirmed by ${ }^{1} \mathrm{H}$ and ${ }^{13} \mathrm{C}$ NMR spectral analyses. The substances were dissolved in 1 to $3 \%$ DMSO (Soares et al., 2014).

\section{Microorganisms}

Paracoccidioides brasiliensis S1 isolate 18 (Pb18-chronic PCM/São Paulo, Brazil), P. brasiliensis S2 (02-chronic PCM/Venezuela), and P. lutzii Pb01-strain ATCC MYA-826 (acute PCM/Goiânia, Brazil) were obtained from the mycology collection of the Mycology Laboratory, School of Pharmaceutical Sciences and were maintained in Fava-Netto agar medium at $37^{\circ} \mathrm{C}$.

\section{Minimum Inhibitory Concentration (MIC)}

The MIC assay was performed according to the microdilution method described by Clinical and Laboratory Standards Institute (CLSI, 2008) document M27-A3 with modifications (de Paula e Silva et al., 2013). Alkyl derivatives of protocatechuic acid (hexyl, heptyl, octyl, nonyl, decyl, and dodecyl protocatechuates) were diluted according to CLSI M27-S3. The yeast suspension was adjusted to a final concentration of $1.5 \times 10^{3} \mathrm{CFU} / \mathrm{mL}$ in RPMI-1640 medium (Sigma-Aldrich, St. Louis, MO, United States) in 96-well plates and serial dilutions (from 250 to $0.24 \mu \mathrm{g} / \mathrm{mL}$ ) of the compounds were then added; $\mathrm{AMB}$ and ITC were used as controls. The plates were incubated on a shaker at $37^{\circ} \mathrm{C} / 150 \mathrm{rpm}$ for a specific duration individually determined for each microorganism. The MIC was determined using alamar blue (Sigma-Aldrich, St. Louis, MO, United States) at 530 and $570 \mathrm{~nm}$; a change from the original blue color of the reagent to pink confirmed death or growth inhibition induced by the antifungal compounds. Following 72 or $96 \mathrm{~h}$ of incubation. The Minimum Fungicide Concentration (MFC) was determined by transferring an aliquot from the wells to Brain Heart Infusion (BHI) medium supplemented with $2 \%$ glucose (Difco, BD Biosciences) plates, which were then incubated at $37^{\circ} \mathrm{C}$ for $5-7$ days. The MFC was defined as the concentration that inhibited growth (Soares et al., 2014).

\section{Cytotoxicity Assay}

The cytotoxicity of the protocatechuates was assessed in the MRC5 cell line (MRC5) obtained from the American Type Culture Collection (ATCC; Manassas, VA, United States) and HepG2 cell line obtained from the Biotechnology Laboratory Biotech (UNICAMP, Brazil). The plates were first incubated with $1 \times 10^{5}$ cells per well at $36.5^{\circ} \mathrm{C}$ under $5 \% \mathrm{CO}_{2}$ for $24 \mathrm{~h}$ to form a cell monolayer (Husøy et al., 1993). Compounds were tested at different concentrations ranging from 0.12 to $62.5 \mu \mathrm{g} / \mathrm{mL}$ using serial dilutions in a total volume of $100 \mu \mathrm{L}$ per well. After the $24 \mathrm{~h}$ treatment the cytotoxicity was assessed by the $0.4 \%$ sulforhodamine B (SRB) (Vichai and Kirtikara, 2006). The assay is sensitive and measures the cellular protein content of adherent or suspension cultures in 96-well plates. Cells were fixed with trichloroacetic acid (TCA) and then stained for $30 \mathrm{~min}$ with SRB dissolved in acetic acid. In mildly acidic conditions, SRB binds on basic amino acid residues on TCAfixed cells. The unbound dye is then removed after washing and the dye bound to the protein is solubilized in basic medium (Tris-base). The absorbance was measured at $570 \mathrm{~nm}$. The result of the percentage of viable cells was performed using the following formula: according to Rajpoot et al. (2012) with minor modification.

Viable cells $\%=$ (test mean - hite mean $/$ mean negative control - mean white) $\times 100$

\section{Preparation of the Nanostructured Lipid System (NLS)}

The NLS was prepared according to previously published methodology with modifications (Formariz et al., 2008, 2010). 
The NLS is formed using cholesterol (10\%) as the oily phase; phosphate buffer ( $\mathrm{pH} 7.4 ; 80 \%$ ) as the aqueous phase; and mixed non-ionic surfactant castor oil, polyoxyl-60/PEG-hydrogenated, PS and OS (8: 6: 3 ratio and a final concentration of $10 \%$ of the formulation). The mixture was sonicated (Sonics ${ }^{\circledR}$ VibraCell) at $220 \mathrm{~W}$ for $30 \mathrm{~min}$ in the discontinuous mode with a $30 \mathrm{sec}$ interval in an ice bath. Following sonication, the NLS was centrifuged at $11,180 \times g$ for $15 \mathrm{~min}$ to eliminate the residue released by the titanium rod sonicator. The samples were characterized as a liquid that was optically translucent or opaque.

\section{Preparation of NLS+Dodecyl}

Following NLS preparation, $2 \mathrm{mg}$ of dodecyl protocatechuate (dodecyl) was incorporated into $2 \mathrm{~mL}$ of NLS, resulting in NLS+dodecyl at a final concentration of $1 \mathrm{mg} / \mathrm{mL}$, which was homogenized and sonicated for $20 \mathrm{~min}$ under the same conditions used in NLS preparation. Subsequently, the NLS+dodecyl was centrifuged at $11,180 \times g$ for $15 \mathrm{~min}$ to eliminate the residue released by the titanium rod sonicator. The formulations were then passed through a $0.22 \mu \mathrm{m}$ sterile filter (Millipore). The mean diameter, PDI, and zeta potential of the NLS and NLS+dodecyl were characterized by using the Zetasizer Nano NS model (Malvern Instruments, Malvern, United Kingdom).

\section{Characterization of the Physicochemical Properties of the Nanoparticles: Determination of Diameter Mean, PDI, and Zeta Potential}

Droplet diameter, PDI, and zeta potential, were determined with and without dodecyl. All samples were diluted: $10 \mu \mathrm{L}$ of sample in $900 \mu \mathrm{L}$ of deionized water. The samples were analyzed using dynamic light scattering with a wavelength of $633 \mathrm{~nm}$ at both $25^{\circ} \mathrm{C}$ and an angle of $90^{\circ}$ at $25^{\circ} \mathrm{C}$ with a Zetasizer Nano ZS particle analyzer (Malvern Instruments, Malvern, United Kingdom) coupled to a multi-purpose titrator. Ten measurements were evaluated for diameter, PDI, and zeta potential; this assay was based on the Doppler Effect (Csaba et al., 2009).

\section{High Resolution Scanning Microscopy (FEG/SEM)}

High resolution scanning microscopy was applied to determine the microstructure of the NLS and NLS+dodecyl. All sample was first lyophilized and suspended in water and then placed on a carbon-coated copper grid. The SEM images were obtained using a JEOL JSM-7500F microscope.

\section{Formation and Inhibition of $P$. brasiliensis 18 Adhesion to the Artificial Extracellular Matrix (ECM)}

Initially, 24-well plates were coated with ECM of fibronectin and laminin, respectively (Sigma-Aldrich, St. Louis, MO, United States) at a concentration of $50 \mu \mathrm{g} / \mathrm{mL}$ for $18 \mathrm{~h}$ at $4^{\circ} \mathrm{C}$ followed by incubation for $1 \mathrm{~h}$ at $37^{\circ} \mathrm{C}$. The plates were then washed three times with PBS and fungal suspension was added at a concentration of $1.5 \times 10^{3} \mathrm{CFU} / \mathrm{mL}$, which had been inoculated into the 24 -well plate previously sensitized with ECM and incubated at $37^{\circ} \mathrm{C}$ for 1,3 , or $5 \mathrm{~h}$. Subsequently, the supernatant was removed, the plate was washed with PBS, and then $300 \mu \mathrm{L}$ of trypsin was added (Sigma). The supernatant was obtained and then centrifuged at 10,000 rpm for $5 \mathrm{~min}$ at $\left(4^{\circ} \mathrm{C}\right)$. The new supernatant was discarded and $500 \mu \mathrm{L}$ of FACS buffer was added for subsequent cell counting by flow cytometry (BD FACS Canto and BD FACS Diva software analysis). Following the adhesion period, treatment with the selected compound (dodecyl and NLS+dodecyl) was performed for $24 \mathrm{~h}$ at $37^{\circ} \mathrm{C}$. RPMI-1640 with L-glutamine and $2 \%$ glucose was used to maintain adequate nutritional status. Subsequently, the supernatant was removed and the plate was washed with PBS. Then, $300 \mu \mathrm{L}$ of trypsin was added and centrifuged. The supernatant was discarded and $500 \mu \mathrm{L}$ of FACS buffer was added to each tube for subsequent cell counting by flow cytometry (BD FACS Canto and BD FACS Diva software analysis).

\section{Inhibition of $P$. brasiliensis 18 Adhesion to Cells}

Cells (MRC5) were cultured at $36.5^{\circ} \mathrm{C}$ in 24-well plates and adjusted to $1 \times 10^{5}$ cells per well. A P. brasiliensis suspension $\left(1.5 \times 10^{3} \mathrm{CFU} / \mathrm{mL}\right)$ was labeled with $10 \mu \mathrm{M}$ of 5(6)-carboxyfluorescein diacetate $\mathrm{N}$-succinimidyl ester (CFSE; Sigma-Aldrich) and then added to the cells. The plate was incubated for $3 \mathrm{~h}$ at $36.5^{\circ} \mathrm{C}$ under $5 \% \mathrm{CO}_{2}$ to enable the adhesion process. Subsequent to treatment, dodecyl and NLS+dodecyl were applied and the plate was incubated for $24 \mathrm{~h}$ under the same conditions. The supernatant was removed and the plate was washed with PBS. Then, $300 \mu \mathrm{L}$ of trypsin (Sigma-Aldrich,) was added and centrifuged. The supernatant was discarded and $500 \mu \mathrm{L}$ of FACS buffer was added to each tube, for subsequent cell counting by flow cytometry (BD FACS Canto) and BD FACS Diva software analysis (Mendes-Giannini et al., 1994, 2004; Hanna et al., 2000).

\section{Toxicity Assay in C. elegans Model}

Caenorhabditis elegans wild-type strain $\mathrm{N} 2$ was routinely cultured at $22^{\circ} \mathrm{C}$ on nematode growth medium (NGM) plates seeded with E. coli strain OP50. For the toxicity assay, eggs were harvested to obtain synchronous cultures. After 3 days, worms in the L4 stage were washed with M9 buffer. Then, approximately 20 worms were transferred to each well of a 96-wells plate containing $100 \mu \mathrm{L}$ of $60 \%$ M9 buffer, $40 \%$ BHI, $10 \mu \mathrm{g} / \mathrm{mL}$ cholesterol (in ethanol), $200 \mu \mathrm{g} / \mathrm{mL}$ ampicillin, and $90 \mu \mathrm{g} / \mathrm{mL}$ kanamycin. Next, $100 \mu \mathrm{L}$ of dodecyl protocatechuate, NLS, or NLS+dodecyl were added to the medium with final compound concentrations in each well ranging from 0.03 to $125 \mu \mathrm{g} / \mathrm{mL}$. The plate was incubated at $22^{\circ} \mathrm{C}$ for $24 \mathrm{~h}$. Worm survival was evaluated based on mobility and form (worms with a stick shape were considered dead and worms with a sinusoidal shape were considered alive). Images were acquired using an IN Cell Analyzer 2000 (GE Healthcare), microscope $(10 \times)$. 
TABLE 1 | Anti-Paracoccidioides activity, cytotoxicity, and SI of different protocatechuate esters.

\begin{tabular}{|c|c|c|c|c|c|c|c|}
\hline & $\begin{array}{l}\text { Pb18 MIC } \\
(\mu \mathrm{g} / \mathrm{mL})\end{array}$ & $\begin{array}{c}\text { Pb01 MIC } \\
(\mu \mathrm{g} / \mathrm{mL})\end{array}$ & $\begin{array}{c}\text { Pb02 MIC } \\
(\mu \mathrm{g} / \mathrm{mL})\end{array}$ & $\begin{array}{c}\text { MRC5 IC }_{50} \\
(\mu \mathrm{g} / \mathrm{mL})\end{array}$ & $\begin{array}{c}\mathrm{SI} \\
\left(\mathrm{IC}_{50} / \mathrm{MIC} \mathrm{Pb18}\right)\end{array}$ & $\begin{array}{c}\mathrm{SI} \\
\left(\mathrm{IC}_{50} / \mathrm{MIC} \mathrm{Pb01}\right)\end{array}$ & $\begin{array}{c}\mathrm{SI} \\
\left(\mathrm{IC}_{50} / \mathrm{MIC} \text { Pb02) }\right.\end{array}$ \\
\hline hexyl & 3.9 & 7.8 & 1.9 & 29.5 & 7.5 & 3.8 & 15.5 \\
\hline octyl & 0.97 & 0.97 & 1.9 & 33.7 & 34.7 & 34.7 & 17.7 \\
\hline nonyl & 1.9 & 0.97 & 0.48 & 17.7 & 9.3 & 18.2 & 36.9 \\
\hline decyl & 0.97 & 1.9 & 0.48 & 16 & 16.5 & 8.4 & 33.3 \\
\hline AMB & 0.13 & 0.06 & 0.02 & 0.22 & 1.8 & 1.8 & 3.7 \\
\hline ITC & 0.02 & 0.12 & 0.01 & 0.10 & 5.0 & 1.0 & 12.5 \\
\hline
\end{tabular}

MFC = MIC; Pb18, P. brasiliensis 18; Pb01, P. Iutzii 01; Pb02, P. brasiliensis 02; MIC minimum inhibitory concentration); MFC, minimum fungicide concentration; MRC5, human normal pneumocyte cells; IC $50,50 \%$ inhibitory concentration; SI, selectivity index = (IC $50 / M I C)$; AMB, amphotericin B; ITC, itraconazole.

\section{Statistical Analysis}

All of the tests were performed as three independent experiments. Statistical analysis of the data was carried out by analysis of variance (ANOVA) with Bonferroni post-test at a 5\% significance level. The results are expressed as the mean \pm standard deviation (SD). The statistical software used was GraphPad Prism 5.0 (La Jolla, CA, United States).

\section{RESULTS}

\section{Minimum Inhibitory Concentration (MIC) of Protocatechuates}

The antifungal activities of hexyl, heptyl, octyl, nonyl, decyl, and dodecyl protocatechuates were evaluated using $P$. brasiliensis and $P$. lutzii. The determined MICs ranged from 0.48 to $7.8 \mu \mathrm{g} / \mathrm{mL}$ for $P$. lutzii ( $\mathrm{Pb} 01$ ) and $P$. brasiliensis $(\mathrm{Pb} 18)$ and from 0.24 to $1.9 \mu \mathrm{g} / \mathrm{mL}$ for $P$. brasiliensis $(\mathrm{Pb} 02)$. The MICs of $\mathrm{AMB}$ and ITC ranged from 0.02 to $0.12 \mu \mathrm{g} / \mathrm{mL}$ and from 0.008 to $0.12 \mu \mathrm{g} / \mathrm{mL}$, respectively, for the three fungal strains. These results are detailed in Table 1. All protocatechuates showed potent antifungal activity; however, the strongest activity was observed for the dodecyl protocatechuate against the three phylogenetic species, with an MIC of $0.24-0.48 \mu \mathrm{g} / \mathrm{mL}$.

\section{Cytotoxicity Assay with Protocatechuates}

A cytotoxicity assay was performed for all protocatechuates using the $0.4 \%$ sulforhodamine $B$ method with the MRC5 cell line (human pneumocytes). The 50\% inhibitory concentration $\left(\mathrm{IC}_{50}\right)$ ranged from 0.48 to $7.8 \mu \mathrm{g} / \mathrm{mL}$ (Table 1). Dodecyl protocatechuate showed a better SI. The SI is the ratio of the concentration of a substance that induces $50 \%$ cell viability relative to the MIC of the same substance. For strain $\mathrm{Pb02}$ in particular, a maximum SI (74.7) was observed (Table 1). The results are shown in Figure 2.

The MIC values demonstrate high cell viabilities for all the tested derivatives with some variation in cell viability: $99 \%$ for hexyl, 65\% for heptyl, $98 \%$ for octyl, $96 \%$ for nonyl, and
98\% for decyl and dodecyl. Thus, hexyl, nonyl, and dodecyl protocatechuate are the most promising substances because they are less toxic to the cell line, as shown in Figure 2. Statistical analyses indicated that the values were significantly different when comparing the compounds with the positive control $(p<0.001)$.

\section{Characterization of NLS}

The protocatechuates, especially dodecyl, showed a very promising antifungal effect. However, the poor solubility of dodecyl led us to incorporate it into an NLS system in order to improve the pharmacological effect and cell viability and solubility.

Table 2 details the diameter, index polydispersity, and the zeta potential values. The mean values for particle size, polydispersity, and the zeta potential of the nanoparticle were $151.22 \mathrm{~nm}, 0.16$, and $-58.30 \mathrm{mV}$ for NLS and $147.82 \mathrm{~nm}, 0.13$, and $-68 \mathrm{mV} .12$ for NLS+dodecyl.

Figure 3 shows SEM images of NLS+dodecyl; as expected, isolated spherical shaped nanoparticles can be seen at 170,000× magnification.

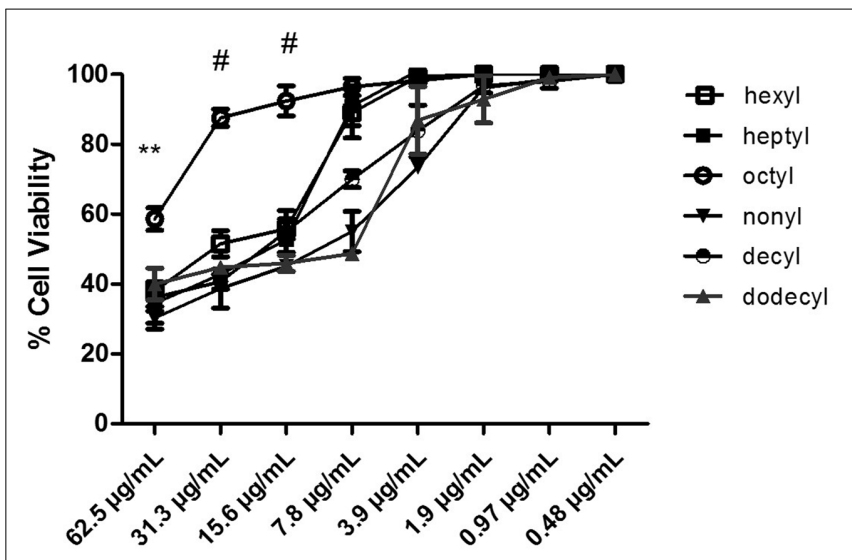

FIGURE 2 | Human normal pneumocyte cells viability (\%) in the presence of protocatechuates (hexyl, heptyl, octyl, nonyl, decyl, and dodecyl). The results are expressed as mean \pm standard deviation $\left({ }^{\#} p<0.001,{ }^{* *} p<0.01\right.$ ). 
TABLE 2 | Evaluation of particle size, polydispersity (PDI), and zeta potential of the NLSs.

\begin{tabular}{lccc}
\hline Formulations & Diameter \pm SD $(\mathbf{n m})$ & PDI \pm SD & Zeta potential \pm SD \\
\hline NLS & $151.22 \pm 0.60$ & $0.16 \pm 0.13$ & $-58.30 \pm 1.04 \mathrm{mV}$ \\
NLS+dodecyl & $147.82 \pm 0.43$ & $0.13 \pm 0.09$ & $-68.12 \pm 1.26 \mathrm{mV}$
\end{tabular}

The mean \pm standard deviation $(S D)$ is provided for 10 determinations of the formulations.

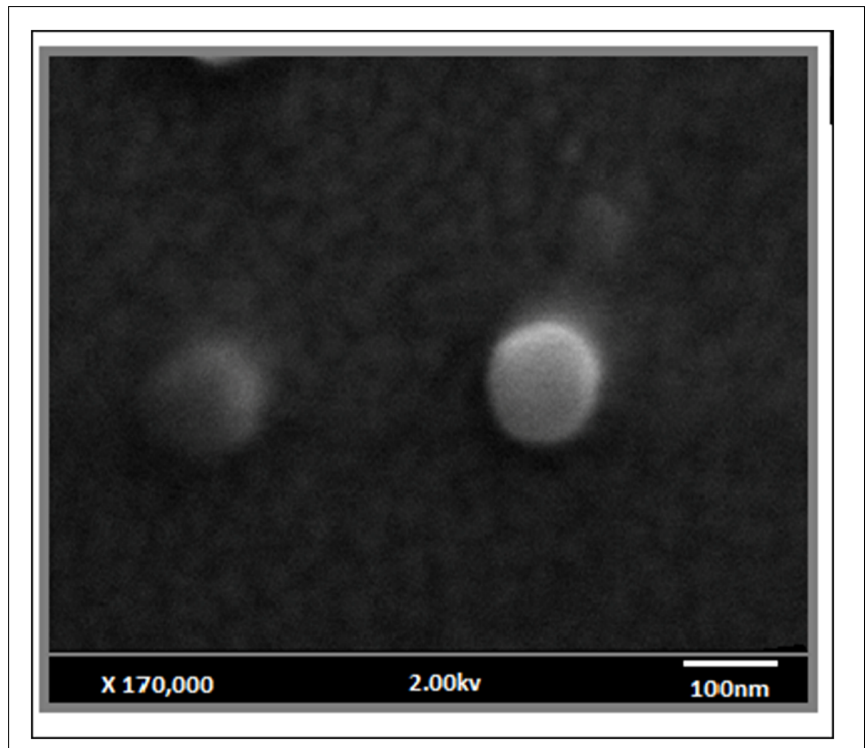

FIGURE 3 | High resolution scanning microscopy images of the NLS loaded with dodecyl (NLS+dodecyl); 170,000× magnification.

\section{Minimum Inhibitory Concentration (MIC) of NLS+Dodecyl Protocatechuate}

The MIC value of loaded dodecyl (NLS+dodecyl) was $0.03 \mu \mathrm{g} / \mathrm{mL}$ for both $P$. lutzii (Pb01) and P. brasiliensis 18 (Pb18) and was $0.06 \mu \mathrm{g} / \mathrm{mL}$ for $P$. brasiliensis 02 (Pb02). NLS+dodecyl exhibited a stronger antifungal activity against the three tested species, with increased MIC values (4- to 16-fold) compared to the MIC of free dodecyl. These results are presented in Table 3.

TABLE 3 | Anti-Paracoccidioides activity and quantitative analysis of dodecyl and amphotericin B (AMB) incorporated into the NLS.

\begin{tabular}{lccc}
\hline $\begin{array}{c}\text { Pb18 MIC } \\
(\mu \mathrm{g} / \mathrm{mL})\end{array}$ & $\begin{array}{c}\text { Pb01 MIC } \\
(\mu \mathrm{g} / \mathrm{mL})\end{array}$ & $\begin{array}{c}\text { Pb02 MIC } \\
(\mu \mathrm{g} / \mathrm{mL})\end{array}$ \\
\hline Dodecyl & 0.48 & 0.48 & 0.24 \\
NLS+dodecyl & 0.03 & 0.03 & 0.06 \\
X increase & 16 & 16 & 4 \\
AMB & 0.13 & 0.06 & 0.12
\end{tabular}

$\overline{M F C}=$ MIC; Pb18, P. brasiliensis 18; Pb01, P. lutzii 01; Pb02, P. brasiliensis 02; $\mathrm{MIC}_{90}$, (90\% minimum inhibitory concentration).

\section{Formation of the Adhesion Curve and Adhesion Inhibition Assay}

The adhesion of $P$. brasiliensis ( $\mathrm{Pb} 18$ ) to ECM components (fibronectin and laminin) was assayed at 1,3 , and $5 \mathrm{~h}$. The greatest adhesion of fungi to ECM was observed at $3 \mathrm{~h}$, which was then used for subsequent experiments (Figures 4A,B). Inhibition of $P$. brasiliensis ( $\mathrm{Pb} 18$ ) adhesion to ECM components (fibronectin and laminin) is shown in Figures 5A,B. Adhesion following 3 and $24 \mathrm{~h}$ of treatment with free dodecyl and dodecyl incorporated into the NLS system was used to establish the MIC values. Adhesion to the fibronectin matrix was 64 and $81 \%$ inhibited by dodecyl and NLS+dodecyl, respectively. The inhibition of adhesion to laminin was 75 and $82.4 \%$ for dodecyl and NLS+dodecyl, respectively. Inhibition of adhesion to the matrix proteins was especially strong when dodecyl was incorporated into the nanostructured system, which increased adhesion inhibition by $17 \%$. The data showed significant differences when compared with the control without treatment $(p<0.05)$.

\section{Inhibition of $P$. brasiliensis-Cell Adhesion Interactions}

Figure 5C demonstrates the inhibition of $P$. brasiliensis $(\mathrm{Pb}$ 18) adhesion to cell lines. Adhesion following 3 and $24 \mathrm{~h}$ of treatment with free dodecyl and dodecyl incorporated into the NLS system were used to establish the MIC value. Adhesion to cells was inhibited by 65 and 74\% by dodecyl and NLS+dodecyl, respectively. Inhibition of cell adhesion was especially strong when dodecyl was incorporated into the nanostructured system, which increased adhesion inhibition by $9 \%$. The data showed significant differences when compared with the control without treatment $(p<0.05)$.

\section{In Vitro Cytotoxicity Assay with NLS and NLS+Dodecyl}

The potential cytotoxic effects of NLS and NLS+dodecyl were assessed with MRC5 (human pneumocytes) and HepG2 cells. NLS, NLS+dodecyl, and free dodecyl affected the cells in a concentration dependent manner. NLS decreased the toxicity of dodecyl in both line cells at higher concentrations $(3.9 \mu \mathrm{g} / \mathrm{mL}$ for MRC5 and $15.6 \mu \mathrm{g} / \mathrm{mL}$ HepG2). The SI of NLS+dodecyl was 295 or 590,4 - to 16 -fold higher compared to the SI free dodecyl (Table 4 and Figure 6).

\section{In Vivo Toxicity}

To further elucidate the potential toxicity of free dodecyl protocatechuate or loaded dodecyl (NLS+dodecyl), we investigated the survival of $C$. elegans exposed to various compound concentrations $(0.03,0.48,7.8,15.6,62.5$, and $125 \mu \mathrm{g} / \mathrm{mL}$ ). Exposure to dodecyl, NLS, and NLS+dodecyl did not affect worm survival at any concentration after $24 \mathrm{~h}$; all worms exhibited a sinusoidal shape and mobility comparable to the untreated worms (Table 5 and Figure 7). 

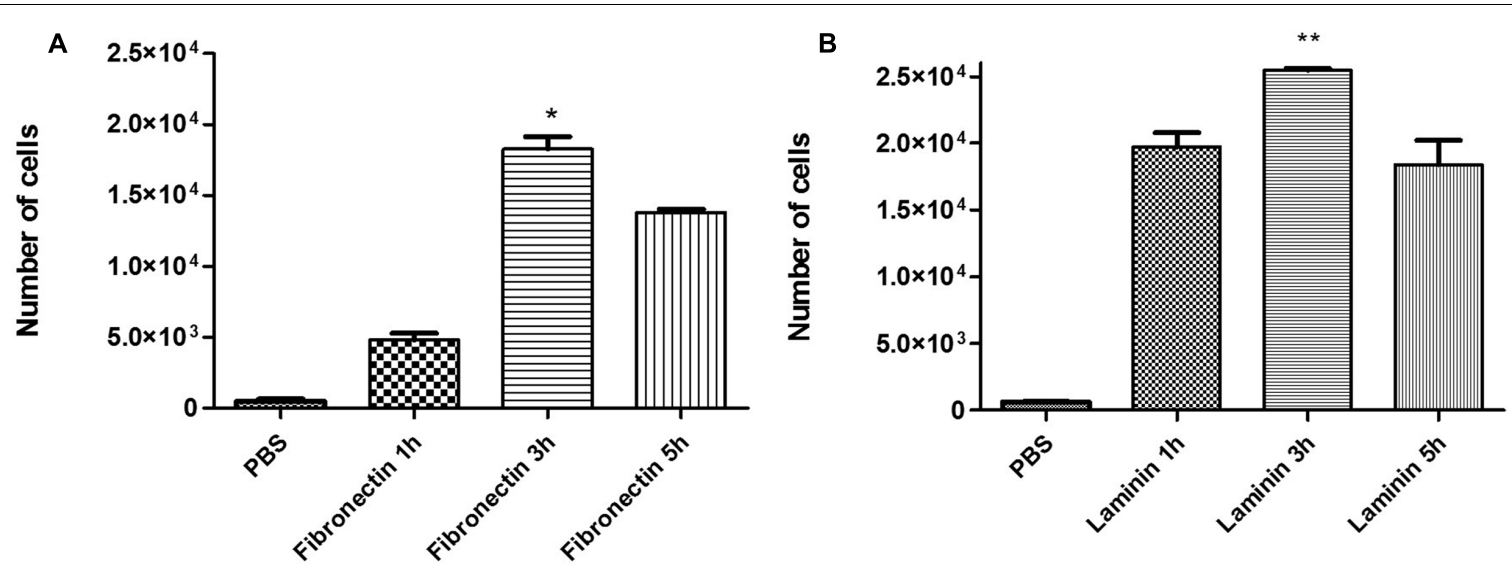

FIGURE 4 | Adhesion curve to (A) the fibronectin matrix and (B) laminin matrix at 1, 3, and $5 \mathrm{~h}$. The results are expressed as mean \pm standard deviation; $\left({ }^{*} p<0.05\right.$, $\left.{ }^{* *} p<0.01\right)$ compared to all time points.
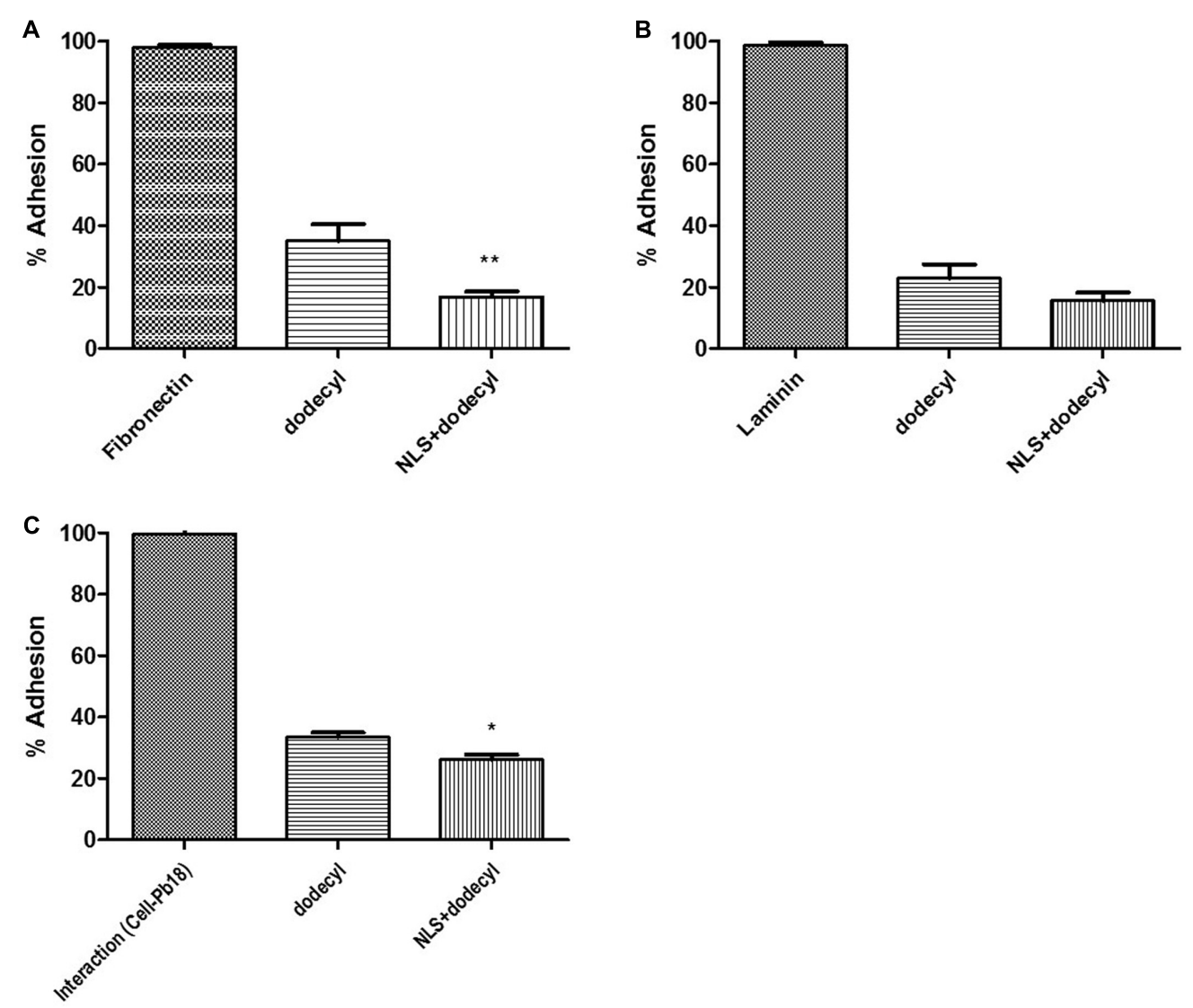

FIGURE 5 | Inhibition of $P$. brasiliensis (Pb 18) adhesion to (A) the fibronectin matrix and (B) the laminin matrix by dodecyl and NLS+dodecyl. (C) Inhibition of $P$. brasiliensis ( $\mathrm{Pb} 18)$ adhesion to cell line MRC5. The results are expressed as the mean \pm standard deviation; $\left({ }^{*} p<0.05,{ }^{* *} p<0.01\right)$ compared to NLS+dodecyl and dodecyl.

\section{DISCUSSION}

Paracoccidioidomycosis treatment can include various antifungal agents such as AMB, azoles (including ITC), and sulfamidic acid; however, prolonged use of these drugs is toxic for patients. Studies with AMB have shown that this drug has several limitations including nephrotoxicity and cell death in patients (Richardson et al., 1988; Brajtburg et al., 1990; Hahn et al., 
TABLE 4 | Cytotoxicity and SI of dodecyl and amphotericin B (AMB) incorporated into the NLS.

\begin{tabular}{|c|c|c|c|c|}
\hline & $\begin{array}{c}\text { MRC5 IC }{ }_{50} \\
(\mu \mathrm{g} / \mathrm{mL})\end{array}$ & $\begin{array}{c}\text { SI (IC }{ }_{50} / \\
\text { MIC Pb18) }\end{array}$ & $\begin{array}{c}\text { SI (IC }{ }_{50} / \\
\text { MIC Pb01) }\end{array}$ & $\begin{array}{c}\mathrm{SI}\left(\mathrm{IC}_{50} /\right. \\
\mathrm{MIC} \mathrm{Pb} 02)\end{array}$ \\
\hline Dodecyl & 17.9 & 37.3 & 37.3 & 74.7 \\
\hline NLS+dodecyl & 17.7 & 590.0 & 590.0 & 295 \\
\hline$X$ increase & - & 16 & 16 & 4 \\
\hline AMB & 0.22 & 1.8 & 1.8 & 3.7 \\
\hline
\end{tabular}

MRC5 (human normal pneumocyte cells); SI (selectivity index) $=\left(I C_{50} / M I C\right), I C_{50}$ (inhibitory concentration 50\%); MIC (minimum inhibitory concentration).

2003; Brime et al., 2004). Thus, there is a need for new therapeutic alternatives comprised of new nanocarrier substances that improve drug release and solubility and decrease compound toxicity (Kreilgaard, 2002; Patel et al., 2009).

In the current study, alkyl derivatives of protocatechuic acid were synthesized and tested for their antifungal activities against a number of Paracoccidioides spp. Our results show that hexyl, heptyl, octyl, nonyl, decyl, and dodecyl protocatechuate have strong antifungal effects against $P$. brasiliensis and P. lutzii; dodecyl protocatechuate showed a highest antifungal activity.

These findings indicate that dodecyl protocatechuate is a highly promising substance because it has a strong antifungal effect with minimal toxicity. Moreover, the results were correlated with the pharmacophore group (3,4-dihydroxybenzoic acid) and intermediate 12-carbon hydrophobic alkyl chain length probably allows increasing antifungal activity (Nihei et al., 2004).

Similarly, reported Nihei et al. (2003) evaluated a series of 3,4dihydroxybenzoate alkyl protocatechuates and their fungicidal activity against Saccharomyces cerevisiae and concluded that the carbon chain plays a key role in antifungal and antioxidant activity.

Previous studies published by our group have shown similar findings for the activity of protocatechuic acid combined with fluconazole against Trichophyton rubrum and T. mentagrophytes. The evaluated compounds (pentyl, hexyl, heptyl, octyl, nonyl, and decyl) showed significant fungicidal effects with MICs ranging from 0.97 to $7.8 \mathrm{mg} / \mathrm{L}$; high fungicidal activity was correlated with
TABLE 5 | Survival percentage of $C$. elegans worms receiving no treatment (control) or treated with NLS (NLS), NLS+dodecyl, or dodecyl protocatechuate at different concentrations. Survival of treated worms is similar to that of the untreated controls.

\begin{tabular}{ccccc}
\hline Concentration $(\boldsymbol{\mu g} / \mathbf{m L})$ & Control & Dodecyl & NLS+dodecyl & NLS \\
\hline & 100 & & & \\
0.03 & & 100 & 100 & 100 \\
0.48 & 100 & 100 & 100 \\
7.80 & 100 & 100 & 100 \\
15.60 & 100 & 100 & 100 \\
62.50 & 100 & 100 & 100 \\
125.00 & 100 & 100 & 100 \\
\hline
\end{tabular}

the hydrophobicity of the lateral chain of the compounds (Soares et al., 2014).

In addition, protocatechuic acid presented good cell viability in the cell lines tested; dodecyl presented the best cell viability and the highest SI, with values from 37.7 to 74.4 . These data indicate that this compound is not toxic because it has an SI above the recommended SI (>10). Thus, dodecyl is more selective for the microorganism and possibly safer for the patient (Orme et al., 2001; de Freitas et al., 2014).

Based on these findings, dodecyl was incorporated into an NLS to increase its biological effects and facilitate its manipulation. The system can help to improve the pharmacokinetic and pharmacodynamic properties of compounds, including enhanced solubility, bioavailability, and stability, as well as protection against toxicity (Pannu et al., 2011; Cerpnjak et al., 2013). The system we developed has taken into account the toxicology of each formulation component with modification (Formariz et al., 2008, 2010).

The NLSs are formed from natural, semisynthetic, and synthetic lipids and contain many structures, such as cholesterol, phospholipids, and OS, which enable better delivery and entrapment because they are atoxic and biocompatible with the drug. However, in order to form a suitable matrix for the NLS, they must be adequately produced because they comprise the matrix of the drug and influence its behavior. The lipids chosen for incorporation must be potentially soluble, stable, and have low
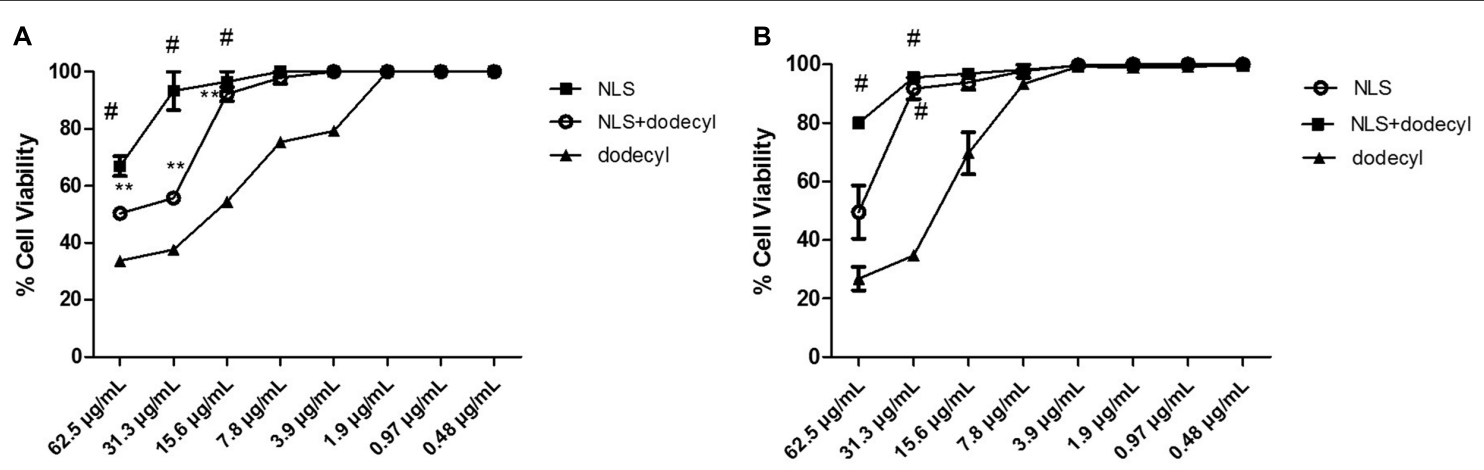

FIGURE 6 | Percentage of Cell Viability results of the SNL (NLS), SNL+ dodecyl (loaded dodecyl) and free dodecyl, in (A) MRC5 and (B) HepG2. The results are expressed as mean \pm standard deviation; $\left({ }^{\#} p<0.001,{ }^{* *} p<0.01\right)$, compared to dodecyl. 


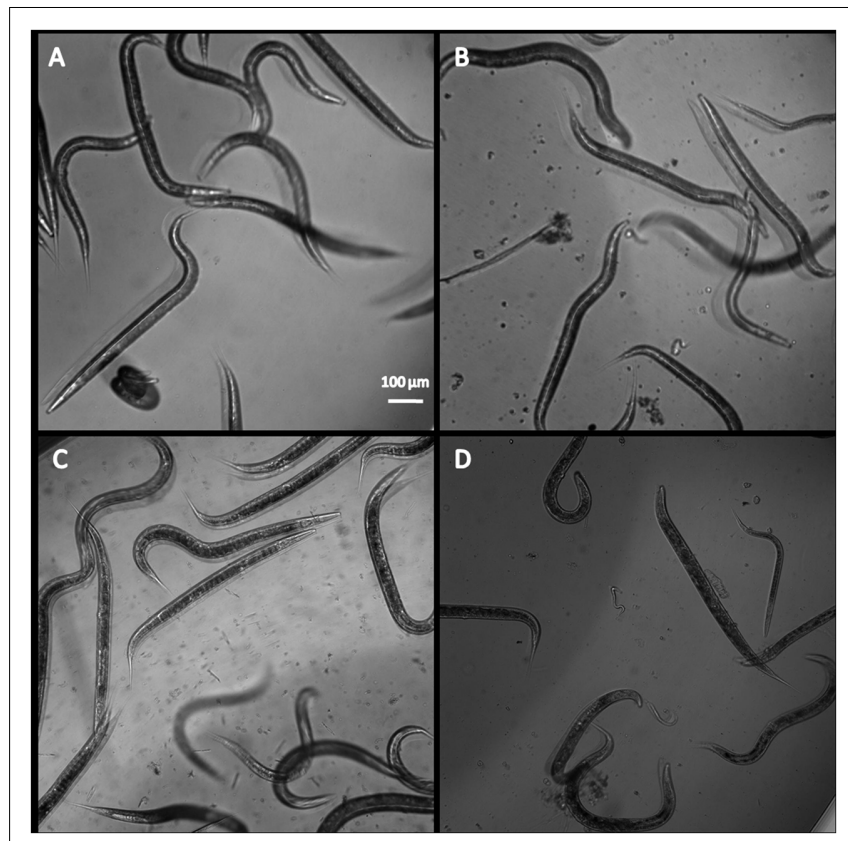

FIGURE 7 | Representative image of C. elegans N2 (A) untreated, treated with (B) NLS, (C) dodecyl protocatechuate, and (D) and NLS+dodecyl.

crystal formation (Müller et al., 2002; Hu et al., 2006; Pardeike et al., 2011).

Thus, we performed a physicochemical characterization of the NLS to determine the particle size (151.22 nm), PDI (0.16), and zeta potential $(-58,30 \mathrm{mV})$. Dodecyl was subsequently incorporated into the system (NLS+dodecyl) resulting in a particle size of $147.82 \mathrm{~nm}$, PDI of 0.13 , and zeta potential of $-68.12 \mathrm{mV}$. This particle size is within the $10-200 \mathrm{~nm}$ range, which are optimum values for the NLS and NLS+dodecyl (Formariz et al., 2005; Goyal et al., 2012). Light scattering analysis showed that the PDI values, calculated by dividing the mean droplet size by the mean number of droplets measured for NLS and NLS+dodecyl, were 0.16 and 0.13 , respectively, indicating optimal good size distribution $(<0.5)$ and reflecting system and NLS+dodecyl droplet size homogeneity (Janes and Alonso, 2003; da Silva et al., 2014). The zeta potential values for NLS and NLS+dodecyl were within the normal range $(-30$ to $+30 \mathrm{mV})$. Negative charges are the result of considerable repulsion between surfaces, which is important to ensure nanodroplet stability because repulsive forces prevent the formation of nanoaggregates. Thus, the system and the drug nanocarrier that are incorporated should be standardized (Legrand et al., 1999; Schaffazick et al., 2003).

The SEM images of NLS+dodecyl revealed spherical shaped particles isolated, where the drug was inserted along the matrix homogeneously, observed in (Figure 3), respectively. Previous studies using a similar technique (ITC loaded into a NLS) observed spherical shape particles following pulmonary application (Pardeike et al., 2011).

The in vitro antifungal activity evaluation demonstrated higher antifungal activity for NLS+dodecyl and an MIC of
$0.06-0.03 \mu \mathrm{g} / \mathrm{mL}$ for the $P$. brasiliensis and $P$. lutzii strains, constituting a 4 - to 16 -fold increase compared to the MIC range of free dodecyl $(0.48-0.24 \mu \mathrm{g} / \mathrm{mL})$. This increase was due to the efficiency of the delivery system and the capacity of the drug to be incorporated into the system matrix.

Subsequently, we evaluated the inhibitory effect of NLS+dodecyl on fungal adhesion to the host, which is the first step of infection. Paracoccidioides spp. can cause mycosis with a variety of clinical manifestations including localized and disseminated forms of the disease that can progress to lethality. Thus, the fungus must have developed mechanisms that enable it to adhere, invade, and pass through the barriers imposed by host tissues (Mendes-Giannini et al., 2000; Marcos et al., 2012). The ability of cells to interact with each other in an orderly manner depends on multiple interactions that allow for adhesion between cells and their extracellular environment; pathogen adherence depends on the recognition of carbohydrates and protein ligands on the surface of the host cell or ECM (Patti and Höök, 1994; Troyanovsky, 1999; Marcos et al., 2012).

In the present study, proteins present in the ECM, namely fibronectin and laminin, were used to examine the ability of free dodecyl protocatechuate and dodecyl incorporated into the nanostructured system to inhibit adhesion. Optimal in vitro adhesion of the fungus to fibronectin and laminin was observed at $3 \mathrm{~h}$. Dodecyl and NLS+dodecyl exhibited 64\% and 81\% inhibition of adhesion to the fibronectin matrix, respectively, and 75 and $82.4 \%$ inhibition of adhesion to the laminin matrix, respectively. Dodecyl induces significant inhibition of adhesion and this inhibition increased up to $17 \%$ in the presence of the nanocarrier. To confirm these inhibition results we next tested the inhibition of $P$. brasiliensis (Pb18) adhesion to cells. Similar results were obtained, with 65 and $74 \%$ inhibition for dodecyl and NLS+dodecyl, respectively, a $9 \%$ increase with the NLS; these results indicate that the system potentiates the effect of dodecyl, inhibiting adhesion to the matrix and cells.

The MIC and inhibition of matrix and cell adhesion are significantly reduced for loaded dodecyl (NLS+dodecyl). This may be related to the fact that the system is formed by an oily phase, which contains lipids such as cholesterol and PC. These oily components act as permeation enhancers; contact surface density and droplet size are components that establish a greater area of contact with the surface of the mucosa providing the skin with a high concentration gradient and increasing the permeation of the system with the drug, thereby facilitating access of the drug to the microorganism (Peltola et al., 2003; Barot et al., 2012; Guimarães et al., 2014).

Therefore, the lipid composition of the NLS may have facilitated drug solubilization, thus significantly increasing antifungal activity. Many drugs exhibit increased antifungal activity upon incorporation with such systems; they become more easily soluble and consequently have increased pharmacological activity (Missner and Pohl, 2009; Bonifácio et al., 2015). A similar study of water-insoluble voriconazole incorporated into a microemulsion to improve solubility, resulted in increased permeation of the drug (favoring transdermal rather than dermal administration) against Candida albicans compared with 
the supersaturated solution of voriconazole (El-Hadidy et al., 2012).

In addition, our results can be attributed to the fact that the system can act as a drug reservoir enabling drug release from the internal phase to the outer phase during microorganism adhesion; this is facilitated by the oil phase of the system that is likely involved in the interaction with components of the fungal cell membrane, such as ergosterol, destabilizing its integrity and causing inhibition of adhesion and consequently parasite lysis and death (Cunha Júnior et al., 2003; Nirmala et al., 2013). A similar study showed that the NB002 nanoemulsion inhibited C. albicans and dermatophyte strains, suggesting that it could be acting via inhibition of ergosterol, leading to fungal death (Pannu et al., 2009).

The cytotoxicity results showed higher than $90 \%$ cellular viability for the system (NLS) and for NLS+dodecyl and did not show cytotoxic effects in cell lines (MRC5 and HepG2) even at high concentrations, in contrast to free dodecyl. These results demonstrate that NLS is a biocompatible formulation that is safe for use in eukaryotic cells; natural lipids are well tolerated by living organisms (Huang, 2008; Abbasalipourkabirreh et al., 2011; Oliveira et al., 2015). The SI is calculated by dividing the $\mathrm{IC}_{50}$ value by the MIC value. An SI $\geq 10$ indicates that the compound can be applied at a concentration that is 10 -fold higher than the MIC value without exhibiting cytotoxicity (Orme et al., 2001).

Our SI results revealed values $>10$. Loaded dodecyl (NLS+dodecyl), for example, presented an SI of 147, 16-fold higher than the SI of free dodecyl. Moreover, NLS+dodecyl has been shown to be more selective for the pathogen and is better tolerated by the host. This is because NLS+dodecyl contains cholesterol and other membrane lipids that promote the interaction with the cellular membrane, facilitating drug delivery to the place of action, without causing toxicity (de Freitas et al., 2014; Oliveira et al., 2015).

Subsequently, we tested free dodecyl protocatechuate and incorporated dodecyl (NLS+dodecyl) in a C. elegans model; neither compound exhibited a toxic effect on survival, indicating they were safe for use in the alternative C. elegans model. C. elegans was first used as an in vivo toxicity model for heavy metals (Williams and Dusenbery, 1988). More recently, toxicity assays using this nematode have been validated as good predictors for the adverse effects of many compounds, including antifungals and nanoparticles, in mammalian species (Okoli et al., 2009; Contreras et al., 2014; Rogers et al., 2015; Muhammed et al., 2016). This is important because of evidence suggesting that the basic

\section{REFERENCES}

Abbasalipourkabirreh, K., Salehzadeh, A., and Abdullah, R. (2011). Cytotoxicity of solid lipid nanoparticles on human breast cancer cell lines. Biotechnology 10, 528-533. doi: 10.3923/biotech.2011.528.533

Alvarenga, J. A., Martins, D. E., Kanas, M., Elizeche, H. G., Dell'Aquila, A. M., Fernandes, E. A., et al. (2016). Paracoccidioidomycosis in the spine: case report and review of the literature. Sao Paulo Med. J. 134, 263-267. doi: 10.1590/15163180.2015.02691801 physiological processes and stress responses in higher organisms (e.g., humans) and C. elegans are similar (Kaletta and Hengartner, 2006).

Based on our results we conclude that dodecyl exhibits antifungal activity, inhibits host-parasite adhesion in matrix and in cells without toxicity in vitro and in vivo, has normal SI values, and that incorporation into the NLS greatly improves these biological effects. Our results suggest that the NLS can be used as a strategy to solubilize drugs and improve antifungal activity against $P$. brasiliensis and $P$. lutzii in vitro and that NLS+dodecyl may constitute a very promising antifungal candidate for the treatment of PCM.

\section{AUTHOR CONTRIBUTIONS}

KM-A performed the tests: MIC, Cytotoxicity assay, Preparation of NLS, Characterization of the physicochemical properties of the nanoparticles, Adhesion of $P$. brasiliensis to artificial ECM and inhibition of adhesion in cell and writing of the manuscript. JS performed Toxicity assay in C. elegans model assay and writing of the manuscript. AV performed inhibition of adhesion in matrix and writing of the manuscript. JS performed the standardization of the adhesion and writing curve of the manuscript. MP prepared and characterized the Protocatechuate. MS prepared and characterized the Protocatechuate. CP preparated and characterized the Protocatechuate. LR professor guided in the Preparation and characterization of Protocatechuate and corrected the manuscript. VB professor oriented in the Preparation and characterization of Protocatechuate and corrected the manuscript. DdS professor oriented in the preparation and characterization of Protocatechuate and corrected the manuscript. MC professor of nanotechnology oriented in the preparation and characterization of the system and corrected the manuscript. MM-G professor guided in the biological tests and corrected the manuscript. AF-A professor guided in the biological tests and corrected the manuscript.

\section{FUNDING}

This work was supported by Conselho Nacional de Pesquisa e Desenvolvimento (CNPq); Fundação de Amparo à Pesquisa do Estado de São Paulo (FAPESP); Coordenação de Aperfeiçoamento de Pessoal de Nível Superior (CAPES) and Programa de Apoio ao Desenvolvimento Científico da Faculdade de Ciências Farmacêuticas da UNESP (PADC/FCF).

Barot, B. S., Parejiya, P. B., Patel, H. K., Gohel, M. C., and Shelat, P. K. (2012). Microemulsion-based gel of terbinafine for the treatment of onychomycosis: optimization of formulation using D-optimal design. AAPS PharmSciTech 13, 184-192. doi: 10.1208/s12249-0119742-7

Benard, G., Campos, A. F., Netto, L. C., Gonçalves, L. G., Machado, L. R., Mimicos, E. V., et al. (2012). Treatment of severe forms of paracoccidioidomycosis: is there a role for corticosteroids? Med. Mycol. 50, 641-648. doi: 10.3109/ 13693786.2011.654135 
Bocca, A. L., Amaral, A. C., Teixeira, M. M., Sato, P. K., Sato, P., Shikanai-Yasuda, M. A., et al. (2013). Paracoccidioidomycosis: eco-epidemiology, taxonomy and clinical and therapeutic issues. Future Microbiol. 8, 1177-1191. doi: 10.2217/ fmb. 13.68

Bonifácio, B. V., Ramos, M. A., da Silva, P. B., Negri, K. M., de Oliveira Lopes, É, de Souza, L. P., et al. (2015). Nanostructured lipid system as a strategy to improve the anti-Candida albicans activity of Astronium sp. Int. J. Nanomedicine 10, 5081-5092. doi: 10.2147/IJN.S79684

Brajtburg, J., Powderly, W. G., Kobayashi, G. S., and Medoff, G. (1990). Amphotericin B: current understanding of mechanisms of action. Antimicrob. Agents Chemother. 34, 183-188. doi: 10.1128/AAC.34.2.183

Brime, B., Molero, G., Frutos, P., and Frutos, G. (2004). Comparative therapeutic efficacy of a novel lyophilized amphotericin B lecithin-based oil-water microemulsion and deoxycholate-amphotericin B in immunocompetent and neutropenic mice infected with Candida albicans. Eur. J. Pharm. Sci. 22, 451-458. doi: 10.1016/j.ejps.2004.04.008

Cerpnjak, K., Zvonar, A., Gašperlin, M., and Vreèer, F. (2013). Lipid-based systems as a promising approach for enhancing the bioavailability of poorly watersoluble drugs. Acta Pharm. 63, 427-445. doi: 10.2478/acph-2013-0040

CLSI (2008). Reference Method for Broth Dilution Antifungal Susceptibility Testing of Yeasts. CLSI document M27-A3, 3rd Edn. Wayne, PA: Clinical and Laboratory Standards Institute.

Colombo, A. L., Tobón, A., Restrepo, A., Queiroz-Telles, F., and Nucci, M. (2011). Epidemiology of endemic systemic fungal infections in Latin America. Med. Mycol. 49, 785-798. doi: 10.3109/13693786.2011.577821

Contreras, E. Q., Puppala, H. L., Escalera, G., Zhong, W., and Colvin, V. L. (2014). Size-dependent impacts of silver nanoparticles on the lifespan, fertility, growth, and locomotion of Caenorhabditis elegans. Environ. Toxicol. Chem. 33, 2716-2723. doi: 10.1002/etc.2705

Csaba, N., Koping-Hoggard, M., and Alonso, M. (2009). Ionically crosslinked chitosan/ tripolyphoshpate nanoparticle of oligonucleotide and plasmid DNA delivery. Int. J. Pharm. 382, 205-214. doi: 10.1016/j.ijpharm.2009.07.028

Cunha Júnior, A. S. C., Fialho, S. L., Carneiro, L. B., and Orefice, F. (2003). Microemulsions as drug delivery systems for topical ocular administration. Arq. Bras. Oftalmol. 66, 385-391. doi: 10.1590/S0004-27492003000300025

da Silva, G. B., Scarpa, M. V., Rossanezi, G., do Egito, E. S., and de Oliveira, A. G. (2014). Development and characterization of biocompatible isotropic and anisotropic oil-in-water colloidal dispersions as a new delivery system for methyl dihydrojasmonate antitumor drug. Int. J. Nanomedicine 9, 867-876. doi: 10.2147/IJN.S46055

de Faria, C. M., Nazaré, A. C., Petrônio, M. S., Paracatu, L. C., Zeraik, M. L., Regasini, L. O., et al. (2012). Protocatechuic acid alkyl esters: hydrophobicity as a determinant factor for inhibition of NADPH oxidase. Curr. Med. Chem. 19, 4885-4893. doi: 10.2174/092986712803341557

de Freitas, E. S., da Silva, P. B., Chorilli, M., Batista, A. A., de Oliveira Lopes, E., da Silva, M. M., et al. (2014). Nanostructured lipid systems as a strategy to improve the in vitro cytotoxicity of ruthenium(II) compounds. Molecules 19, 5999-6008. doi: 10.3390/molecules19055999

de Oliveira, H. C., Assato, P. A., Marcos, C. M., Scorzoni, L., de Paula E Silva, A. C. Da Silva Jde, F., et al. (2015). Paracoccidioides-host interaction: an overview on recent advances in the paracoccidioidomycosis. Front. Microbiol. 6:1319. doi: 10.3389/fmicb.2015.01319

de Paula e Silva, A. C., Oliveira, H. C., Silva, J. F., Sangalli-Leite, F., Scorzoni, L., Fusco-Almeida, A. M., et al. (2013). Microplate alamarBlue assay for Paracoccidioides susceptibility testing. J. Clin. Microbiol. 51, 1250-1252. doi: 10.1128/JCM.02914-12

de Souza, S. P., Jorge, V. M., and Xavier, M. O. (2014). Paracoccidioidomycosis in southern Rio Grande do Sul: a retrospective study of histopathologically diagnosed cases. Braz. J. Microbiol. 45, 243-247.

El-Hadidy, G. N., Ibrahim, H. K., Mohamed, M. I., and El-Milligi, M. F. (2012). Microemulsions as vehicles for topical administration of voriconazole: formulation and in vitro evaluation. Drug Dev. Ind. Pharm. 38, 64-72. doi: 10.3109/03639045.2011.590731

Formariz, T. P., Chiavacci, L. A., Sarmento, V. H., Franzini, C. M., Silva-, A. A., Scarpa, M. V., et al. (2008). Structural changes of biocompatible neutral microemulsions stabilized by mixed surfactant containing soya phosphatidylcholine and their relationship with doxorubicin release. Colloids Surf. B Biointerfaces 63, 287-295. doi: 10.1016/j.colsurfb.2007.12.021
Formariz, T. P., Chiavacci, L. A., Scarpa, M. V., Silva-Júnior, A. A., Egito, E. S., Terrugi, C. H., et al. (2010). Structure and viscoelastic behavior of pharmaceutical biocompatible anionic microemulsions containing the antitumoral drug compound doxorubicin. Colloids Surf. B Biointerfaces 77, 47-53. doi: 10.1016/j.colsurfb.2010.01.004

Formariz, T. P., Urban, C. C., Silva Júnior, A. A., Gremião, M. P. D., and Oliveira, A. G. (2005). Microemulsion and liquid crystals as drug delivery systems. Rev. Bras. Cien Farm 41, 301-331.

González, A., Gómez, B. L., Diez, S., Hernández, O., Restrepo, A., Hamilton, A. J., et al. (2005). Purification and partial characterization of a Paracoccidioides brasiliensis protein with capacity to bind to extracellular matrix proteins. Infect. Immun. 73, 2486-2495. doi: 10.1128/IAI.73.4.2486-2495.2005

Goyal, U., Arora, R., and Aggarwal, G. (2012). Formulation design and evaluation of a self-microemulsifying drug delivery system of lovastatin. Acta Pharm. 62, 357-370. doi: 10.2478/v10007-012-0022-1

Guimarães, G. P., de Freitas Araújo Reis, M. Y., da Silva, D. T., Junior, F. J., Converti, A., Pessoa, A., et al. (2014). Antifungal activity of topical microemulsion containing a thiophene derivative. Braz. J. Microbiol. 45, 545-550. doi: 10.1590/S1517-83822014000200024

Hahn, R. C., Morato Conceição, Y. T., Santos, N. L., Ferreira, J. F., and Hamdan, J. S. (2003). Disseminated paracoccidioidomycosis: correlation between clinical and in vitro resistance to ketoconazole and trimethoprim sulphamethoxazole. Mycoses 46, 342-347. doi: 10.1046/j.1439-0507.2003.00901.x

Hanna, S. A., Monteiro da Silva, J. L., and Giannini, M. J. (2000). Adherence and intracellular parasitism of Paracoccidioides brasiliensis in Vero cells. Microbes Infect. 2, 877-884. doi: 10.1016/S1286-4579(00)00390-7

Hernández, O., Tamayo, D., Torres, I., McEwen, J. G., and García, A. M. (2011). Kinetic analysis of gene expression during mycelium to yeast transition and yeast to mycelium germination in Paracoccidioides brasiliensis. Biomedica 4, 570-579. doi: 10.1590/S0120-41572011000400012

Hu, F. Q., Jiang, S. P., Du, Y. Z., Yuan, H., Ye, Y. Q., and Zeng, S. (2006). Preparation and characteristics of monostearin nanostructured lipid carriers. Int. J. Pharm. 314, 83-89. doi: 10.1016/j.ijpharm.2006.01.040

Huang, Z. R. (2008). Development and evaluation of lipid nanopar- ticles for camptothecin delivery: a comparison of solid lipid nanoparticles, nanostructured lipid carriers, and lipid emulsion. Acta Pharmacol. Sin. 29, 1094-1102. doi: 10.1111/j.1745-7254.2008.00829.x

Husøy, T., Syversen, T., and Jenssen, J. (1993). Comparisons of four in vitro cytotoxicity tests: The MTT assay, NR assay, uridine incorporation and protein measurements. Toxicol. In Vitro 7, 149-154. doi: 10.1016/0887-2333(93) 90125-O

Hussain, A., Samad, A., Nazish, I., and Ahmed, F. J. (2014). Nanocarrier-based topical drug delivery for an antifungal drug. Drug Dev. Ind. Pharm. 40, 527-541. doi: 10.3109/03639045.2013.771647

Janes, K., and Alonso, M. J. (2003). Depolymerized chitosan nanoparticle for protein delivery: preparation and characterization. J. Appl. Polym Sci. 88, 2769-2776. doi: 10.1002/app.12016

Kaletta, T., and Hengartner, M. O. (2006). Finding function in novel targets: C. elegans as a model organism. Nat. Rev. Drug Discov. 5, 387-398. doi: 10.1038/ $\operatorname{nrd} 2031$

Khan, A. K., Rashid, R., Fatima, N., Mahmood, S., Mir, S., Khan, S., et al. (2015). Pharmacological activities of protocatechuic acid. Acta Pol. Pharm. 72, 643-650.

Kreilgaard, M. (2002). Influence of microemulsions on cutaneous drug delivery. Adv. Drug Deliv. Rev. 54(Suppl. 1), S77-S98. doi: 10.1016/s0169-409x(02) 00116-3

Legrand, P., Barratt, G., Mosqueira, V. D. F., Fessi, H., and Devissaguet, F. (1999). Polymeric nanocapsule as drugs delivery sistem. Pharm. Sci. 9, 411-418.

Lin, C. Y., Huang, C. S., Huang, C. Y., and Yin, M. C. (2009). Anticoagulatory, antiinflammatory, and antioxidative effects of protocatechuic acid in diabetic mice. J. Agric. Food Chem. 57, 6661-6667. doi: 10.1021/jf9015202

Lortholary, O., Denning, D. W., and Dupont, B. (1999). Endemic mycoses: a treatment update. J. Antimicrob. Chemother. 43, 321-331. doi: 10.1093/jac/43. 3.321

Marcos, C. M., de Fátima da Silva, J., de Oliveira, H. C., Moraes da Silva, R. A., Mendes-Giannini, M. J., and Fusco-Almeida, A. M. (2012). Surfaceexpressed enolase contributes to the adhesion of Paracoccidioides brasiliensis to host cells. FEMS Yeast Res. 12, 557-570. doi: 10.1111/j.1567-1364.2012. 00806.x 
Mendes-Giannini, M. J., Hanna, S. A., da Silva, J. L., Andreotti, P. F., Vincenzi, L. R., Benard, G., et al. (2004). Invasion of epithelial mammalian cells by Paracoccidioides brasiliensis leads to cytoskeletal rearrangement and apoptosis of the host cell. Microbes Infect. 6, 882-891. doi: 10.1016/j.micinf.2004.05.005

Mendes-Giannini, M. J., Ricci, L. C., Uemura, M. A., Toscano, E., and Arns, C. W. (1994). Infection and apparent invasion of Vero cells by Paracoccidioides brasiliensis. J. Med. Vet. Mycol. 32, 189-197. doi: 10.1080/02681219480000251

Mendes-Giannini, M. J., Taylor, M. L., Bouchara, J. B., Burger, E., Calich, V. L., Escalante, E. D., et al. (2000). Pathogenesis II: fungal responses to host responses: interaction of host cells with fungi. Med. Mycol. 38, 113-123. doi: 10.1080/mmy.38.s1.113.123

Missner, A., and Pohl, P. (2009). 110 years of the Meyer-Overton rule: predicting membrane permeability of gases and other small compounds. Chemphyschem 10, 1405-1414. doi: 10.1002/cphc. 200900270

Muhammed, M., Arvanitis, M., and Mylonakis, E. (2016). Whole animal HTS of small molecules for antifungal compounds. Expert Opin. Drug Discov. 11, 177-184. doi: 10.1517/17460441.2016.1122591

Müller, R. H., Radtke, M., and Wissing, S. A. (2002). Nanostructured lipid matrices for improved microencapsulation of drugs. Int. J. Pharm. 242, 121-128. doi: 10.1016/S0378-5173(02)00180-1

Naranjo, T. W., Lopera, D. E., Diaz-Granados, L. R., Duque, J. J., Restrepo, A., and Cano, L. E. (2010). Histopathologic and immunologic effects of the itraconazole treatment in a murine model of chronic pulmonary paracoccidioidomycosis. Microbes Infect. 12, 1153-1162. doi: 10.1016/j.micinf.2010.07.013

Nasr, M., Nawaz, S., and Elhissi, A. (2012). Amphotericin B lipid nanoemulsion aerosols for targeting peripheral respiratory airways via nebulization. Int. J. Pharm. 436, 611-616. doi: 10.1016/j.ijpharm.2012.07.028

Nihei, K., Nihei, A., and Kubo, I. (2003). Rational design of antimicrobial agents: antifungal activity of alk(en)yl dihydroxybenzoates and dihydroxyphenyl alkanoates. Bioorg. Med. Chem. Lett. 13, 3993-3996. doi: 10.1016/j.bmcl.2003. 08.057

Nihei, K., Nihei, A., and Kubo, I. (2004). Molecular design of multifunctional food additives: antioxidative antifungal agents. J. Agric. Food Chem. 52, 5011-5020. doi: $10.1021 /$ jf049687n

Nirmala, M. J., Mukherjee, A., and Chandrasekaran, N. (2013). Improved efficacy of fluconazole against candidiasis using bio-based microemulsion technique. Biotechnol. Appl. Biochem. 60, 417-429. doi: 10.1002/bab.1116

Nishioka, S. A. (1996). Paracoccidioidomycosis and AIDS. Clin. Infect. Dis. 22, 1132-1133. doi: 10.1093/clinids/22.6.1132-a

Okoli, I., Coleman, J. J., Tampakakis, E., Tempakakis, E., An, W. F., Holson, E., et al. (2009). Identification of antifungal compounds active against Candida albicans using an improved high-throughput Caenorhabditis elegans assay. PLoS ONE 4:e7025. doi: 10.1371/journal.pone.0007025

Oliveira, M. B., Calixto, G., Graminha, M., Cerecetto, H., González, M., and Chorilli, M. (2015). Development, characterization, and in vitro biological performance of fluconazole-loaded microemulsions for the topical treatment of cutaneous leishmaniasis. Biomed Res. Int. 2015:396894. doi: 10.1155/2015/ 396894

Orme, I., Secrist, J., Anathan, S., Kwong, C., Maddry, J., and Reynolds, R. (2001). Search for new drugs for treatment of tuberculosis. Antimicrob. Agents Chemother. 45, 1943-1946. doi: 10.1128/AAC.45.7.1943-1946.2001

Pannu, J., McCarthy, A., Martin, A., Hamouda, T., Ciotti, S., Fothergill, A., et al. (2009). NB-002, a novel nanoemulsion with broad antifungal activity against dermatophytes, other filamentous fungi, and Candida albicans. Antimicrob. Agents Chemother. 53, 3273-3279. doi: 10.1128/AAC.00218-09

Pannu, J., McCarthy, A., Martin, A., Hamouda, T., Ciotti, S., Ma, L., et al. (2011). In vitro antibacterial activity of NB-003 against Propionibacterium acnes. Antimicrob. Agents Chemother. 55, 4211-4217. doi: 10.1128/AAC.00561-11

Pardeike, J., Weber, S., Haber, T., Wagner, J., Zarfl, H. P., Plank, H., et al. (2011). Development of an itraconazole-loaded nanostructured lipid carrier (NLC) formulation for pulmonary application. Int. J. Pharm. 419, 329-338. doi: 10.1016/j.ijpharm.2011.07.040

Patel, M. R., Patel, R. B., Parikh, J. R., Solanki, A. B., and Patel, B. G. (2009). Effect of formulation components on the in vitro permeation of microemulsion drug delivery system of fluconazole. AAPS PharmSciTech 10, 917-923. doi: 10.1208/s12249-009-9286-2

Patti, J. M., and Höök, M. (1994). Microbial adhesins recognizing extracellular matrix macromolecules. Curr. Opin. Cell Biol. 6, 752-758. doi: 10.1016/09550674(94)90104-X

Peltola, S., Saarinen-Savolainen, P., Kiesvaara, J., Suhonen, T. M., and Urtti, A. (2003). Microemulsions for topical delivery of estradiol. Int. J. Pharm. 254, 99-107. doi: 10.1016/S0378-5173(02)00632-4

Peterson, R. T., Nass, R., Boyd, W. A., Freedman, J. H., Dong, K., and Narahashi, T. (2008). Use of non-mammalian alternative models for neurotoxicological study. Neurotoxicology 29, 546-555. doi: 10.1016/j.neuro.2008.04.006

Rajpoot, P., Bali, V., and Pathak, K. (2012). Anticancer efficacy, tissue distribution and blood pharmacokinetics of surface modified nanocarrier containing melphalan. Int. J. Pharm. 15, 219-230. doi: 10.1016/j.ijpharm.2012. 01.027

Richardson, S. E., Bannatyne, R. M., Summerbell, R. C., Milliken, J., Gold, R., and Weitzman, S. S. (1988). Disseminated fusarial infection in the immunocompromised host. Rev. Infect. Dis. 10, 1171-1181. doi: 10.1093/ clinids/10.6.1171

Roberts, J., Bingham, J., McLaren, A. C., and McLemore, R. (2015). Liposomal formulation decreases toxicity of amphotericin B In Vitro and In Vivo. Clin. Orthop. Relat. Res. 473, 2262-2269. doi: 10.1007/s11999-015-4232-y

Rogers, S., Rice, K. M., Manne, N. D., Shokuhfar, T., He, K., Selvaraj, V., et al. (2015). Cerium oxide nanoparticle aggregates affect stress response and function in Caenorhabditis elegans. SAGE Open Med. 3:2050312115575387. doi: $10.1177 / 2050312115575387$

San-Blas, G., Niño-Vega, G., and Iturriaga, T. (2002). Paracoccidioides brasiliensis and paracoccidioidomycosis: molecular approaches to morphogenesis, diagnosis, epidemiology, taxonomy and genetics. Med. Mycol. 40, 225-242. doi: $10.1080 /$ mmy.40.3.225.242

Schaffazick, S. R., Pohlmann, A. R., Dalla-Costa, T., and Guterres, S. S. (2003). Freeze-drying polymeric colloidal suspensions: nanocapsules, nanospheres and nanodispersion. A comparative study. Eur. J. Pharm. Biopharm. 56, 501-505. doi: 10.1016/S0939-6411(03)00139-5

Shikanai-Yasuda, M. A. (2015). Paracoccidioidomycosis treatment. Rev. Inst. Med. Trop. Sao Paulo 57(Suppl. 19), 31-37. doi: 10.1590/S0036-46652015000700007

Shikanai-Yasuda, M. A., Telles Filho, F. E. Q., Mendes, R. P., Colombo, A. L., and Moretti, M. L. (2006). Guidelines in paracoccidioidomycosis. Rev. Soc. Bras. Med. Trop. 39, 297-310. doi: 10.1590/S0037-8682200600030 0017

Soares, L. A., Gullo, F. P., Sardi, J. C., Pitangui, N. S., Costa-Orlandi, C. B., Sangalli-Leite, F., et al. (2014). Anti-trichophyton activity of protocatechuates and their synergism with fluconazole. Evid Based Complement Alternat. Med. 2014:957860. doi: 10.1155/2014/957860

Troyanovsky, S. M. (1999). Mechanism of cell-cell adhesion complex assembly. Curr. Opin. Cell Biol. 11, 561-566. doi: 10.1016/S0955-0674(99)00021-6

Vichai, V., and Kirtikara, K. (2006). Sulforhodamine B colorimetric assay for cytotoxicity screening. Nat. Protoc. 1, 1112-1116. doi: 10.1038/nprot.2006.179

Williams, P. L., and Dusenbery, D. B. (1988). Using the nematode Caenorhabditis elegans to predict mammalian acute lethality to metallic salts. Toxicol. Ind. Health 4, 469-478. doi: 10.1177/074823378800400406

Conflict of Interest Statement: The authors declare that the research was conducted in the absence of any commercial or financial relationships that could be construed as a potential conflict of interest.

Copyright (C) 2017 Medina-Alarcón, Singulani, Voltan, Sardi, Petrônio, Santos, Polaquini, Regasini, Bolzani, da Silva, Chorilli, Mendes-Giannini and FuscoAlmeida. This is an open-access article distributed under the terms of the Creative Commons Attribution License (CC BY). The use, distribution or reproduction in other forums is permitted, provided the original author(s) or licensor are credited and that the original publication in this journal is cited, in accordance with accepted academic practice. No use, distribution or reproduction is permitted which does not comply with these terms. 